\title{
Jaw cysts at children and adolescence: A single-center retrospective study of 152 cases in southern Bulgaria
}

\author{
Petia F. Pechalova ${ }^{1}$, Angel G. Bakardjiev ${ }^{2}$, Ani B. Beltcheva ${ }^{3}$ \\ ${ }^{1}$ Department of maxillo-facial surgery, Faculty of Dental Medicine, Medical University, Plovdiv, Bulgaria \\ ${ }^{2}$ Department of oral surgery, Faculty of Dental Medicine, Medical University, Plovdiv, Bulgaria \\ ${ }^{3}$ Department of pediatric dentistry, Faculty of Dental Medicine, Medical University, Plovdiv, Bulgaria
}

\author{
Correspondence: \\ Department of maxillo-facial surgery \\ Faculty of Dental Medicine \\ Medicine University \\ Str. "Peshtersko shose” № 66 \\ Plovdiv, Bulgaria \\ pechalova@abv.bg
}

Received: 20/02/2010

Accepted: $11 / 03 / 2010$

\begin{abstract}
Pechalova PF, Bakardjiev AG, Beltcheva AB. Jaw cysts at children and adolescence: A single-center retrospective study of 152 cases in southern Bulgaria. Med Oral Patol Oral Cir Bucal. 2011 Sep 1;16 (6):e767-71. http://www.medicinaoral.com/medoralfree01/v16i6/medoralv16i6p767.pdf
\end{abstract}

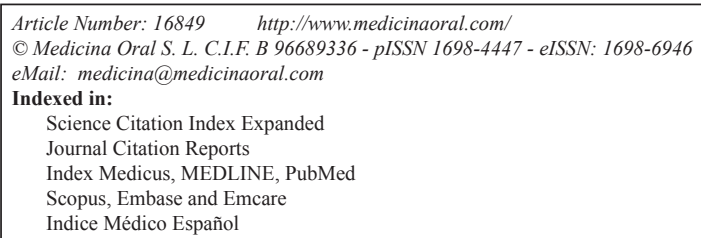

\begin{abstract}
One hundred fifty two cysts of the upper and lower jaw were examined at patients up to 18 years old treated in the Clinics of Maxillo-Facial Surgery, University Hospital, Plovdiv, Bulgaria for the period 1998 - 2007. Patients were distributed in four age groups (up to 4 years old, from 5 to 9 years old, from 10 to 14 years old, from 15 to 18 years old). Both sexes were constantly affected ( $52 \%$ male, $48 \%$ female). The biggest number cystic lesions were found in the third age group (48.7\%). The mandible was preferable localization of the lesions (69.7\%). Dentigerous cysts predominated $(61.8 \%)$ - more affected was third age group (31.6\%). Radicular cysts were observed two times less $(31.6 \%)$ - more affected were third (15.8\%) and fourth (12.5\%) age groups. The most frequently observed clinical symptom was presence of painless swelling (59.9\%). The operative interventions were carried out predominantly under general anesthesia (81.6\%) by intraoral approach (97.4\%). The extraoral surgical approach was preferred in four cases only - three in third and one in fourth age groups.
\end{abstract}

Key words: Jaw cysts, children, adolescence.

\section{Introduction}

Jaw cysts are known from high antiquity. Lesions of the jaws interpreted as cysts were found in mummies, 4500 years b. c. In the beginning of the I-st c.a.c. Aulus Cornelius Celsus described cystic lesions of the jaws. Later Pierre Fauchard (1690 - 1762) and John Hunter (1729 - 1793) published description of jaw cysts. Written reports for the nature and treatment of jaw cysts became more frequent after 1850. In 1866 Paul Broca created classification of odontomas, including odontogenic tumors, cysts and malformations. In 1974 Kramer defined cyst as a "pathological cavity fully or separately epithelized, having fluid, semifluid or gaseous contens and which is not created by the accumulation of pus". Recent century continues enriching knowledge about jaw cysts - the latest classification of World Health Organization (WHO) is done in 2005. WHO defines radicular cysts as pathologic bone cavities with inflammatory genesis, epithelized, developed around teeth's apexes an rarely laterally to the teeth's roots in 
connection with extra lateral root channels. Nair writes about presence of two types radicular cysts - "real", that represent an independent from the microorganism closed system and "pocket" or "cove", connected with the apical foramen and the root channel (1). In the pathogenesis of radicular cysts conventionally can be devided three stages: initiation, formation of epithelium capsule and growth of the cyst.

I. Initiation: Radicular cysts arise out of epithelial cell of Malassez, which proliferation is stimulated by inflammation - a result from pulp necrosis and released necrotic tissue and bacterial antigens the key part among which take the bacterial endotoxines from Actinobacillus actinomycetemcomitans, Porphyromonas gingivalis and Escherichia coli, thought to be the most important initiation factor in pathogenesis of radicular cysts. A substantial meaning for proliferation of epithelial cells of Malassez have the inflammatory cytokines predominant place among which take immunoglobulin (Ig) G, followed by IgA, IgE, IgM (2). In the periapical cysts lymphocytes B and T have been established which suggests that the origin of these legions is a result of immune reactions with participation of cellular and humoral immunity (3). Immunohistochemical studies determine presence of interleukin (IL)-1 $\alpha$, IL-1 $\beta$, IL- 6 in the epithelial cover, in the endothelial cells of the vessels, tumor necrosis factor (TNF) and IL-8 - in macrophages.

II. Formation of epithelial capsule: There are two famous theories. The first one suggests that the proliferating epithelium covers the uncovered connective tissue surface of the abscess's cavity or the surface of the cavity formed as a result of connective tissue destruction under the action of proteolysis enzymes. The other theory which has more upholders says that the cystic cavity is formed after epithelial tissue proliferation in the apical region through degeneration and cells'death in the center. Participation of matrix metalloproteinase (MMP)-13, secreted from epithelial cells, fibroblasts and plasmatic cells is supposed in the development of this process. Important is also the role of MMP-1, MMP-8, MMP-2, MMP-9 (4).

III. Growth of the cyst: It is well known that the pressure of the fluids in the cystic cavity is statistically significant higher than the local blood pressure as the inter cystic pressure is in reverse proportion with the cyst size, which means that it has a leading role in the earliest stages of cyst's growth (5). In the process of cyst's growth participation of glucosaminoglycans is suspected, presented in the cellular wall and cystic contain. It is supposed that the process is attended by destruction of the enclosed connective tissue and bone resorption with participation of prostaglandins. The role of RANKL, found in the cellular wall, has also been established.
Dentigerous cysts embrace fully or partially the crown of unerupted tooth and accomplish a contact with it in the region of cemento-enamel junction. In the literature predominates the statement that dentigerous cyst can be of extra- or intra follicular origin, as the second type develops as a result of fluid accumulation between the reduced enamel epithelium and the enamel as well as in the enamel organ. Another theory for the origin discusses the possibility for falling of the permanent tooth's crown during eruption into dentigerous cyst formed around the apex of its transient predecessor. It has been also discussed the opinion that inflammatory changes in the apex of the transient tooth predecessor can be responsible for developing of dentigerous cysts around the corresponding permanent teeth (6).

The term "odontogenic keratocyst" is proposed by Philipsen in 1956. With the publication of the last classification of jaw cysts WHO recommends the name "odontogenic keratocyst" to be replaced by "keratocystic odontogenic tumour". But the opinion of the International Association of Oral Pathologists from June 2006 is that the name "odontogenic keratocyst" should be preserved until receiving of undisputed evidences in molecular level proving the neoplastic character of the lesion. It arising from epithelial odontogenic rests (7). The typical microscopic characteristic of this lesion is the presence of variable amounts of aberrant epithelial cells, without nuclei, which are named "ghost cells" (8). In the wall of the odontogenic keratocyst a collagenolytic activity is established and later a: polymorphonuclear collagenase is isolated which helps the connective tissue destruction at absence of inflammatory cells by degranulation of sub cellular particles under the action of specific antigen - induced immunocomplex or by direct contact. Basal cell nevus syndrome or Gorlin-Goltz syndrome, an autosomal dominant inherited disorder, with a high penetration, clinically characterised by a series of associated manifestations, the most common being maxillary keratocysts and cutaneous basal cell carcinomas, and other less frequent ones which can be present, such as cardiac disturbances (persistent ductus arteriosus), characteristic facies (mandibular prognathia, marked superciliary arches, wide bridged nose and hypertelorism), skeletal (brachymetacarpalism of the 4th and 5th fingers, vertebrae problems, costal synostosis or bifid ribs), skin (dermoid cysts, lipomas), neurological (congenital hydrocephalus, calcification of the cerebral falx, learning difficulties), sight (blindness, congenital cataracts, strabismus), hormonal (hypogonadism) or associated with other malignant neoplasias (9).

\section{Objective}

The present study was aimed at providing a clinical and epidemiological analysis of patients up to 18 years old with cystic lesions, treated at the Clinics of MaxilloFacial Surgery, University Hospital, Plovdiv, Bulgaria. 


\section{Material and Methods}

The study was conducted over a ten year period - from 1998 through 2007. Analysis was based on patients' clinical records. All patients up to 18 years old with final pathological diagnosis "cyst" of the upper and lower jaw based on World Health Organization classification from 1992 (3) were enrolled in the study. They received treatment at the Clinics of Maxillo-Facial Surgery, University Hospital, Plovdiv, Bulgaria. The following variables were tested: sexual and age distribution, pathological diagnosis, location, reason for diagnosis, type of anesthesia, operative approach. SPSS 11.0 software was used for data processing.

\section{Results}

For the 10-years period 152 dentigerous, radicular, odontogenic keratocysts and nonodontogenic jaw cysts were examined. The cysts were at patients up to 18 years old, distributed in 4 age groups - up to 4 years old, from 5 to 9 years old, from 10 to 14 years old and from 15 to 18 years old. No statistically significant difference in sexual distribution was found -1.08 male: 1 female. The mandible was affected 2.3 times more than the maxilla. Dentigerous cysts were the most frequently established cystic lesions. The patients from the third age group were most often affected. The usual clinical complains of the patients were connected with painless swelling. General anesthesia was 4.4 times more preferable method compared to the local one. Cystectomies made by intraoral operative approach predominate over interventions through extra oral approach in ratio 37 : 1 (Table 1).

\section{Discussion}

Our study established nearly equal sexual distribution. The ratio male: female was 1.08: 1 (79:73). This correlates with the data of Bodner (10) for ratio 1.0 and of Salako and Taiwo (11) and Sousa et al. (12) for lack of significant difference in sexual distribution. The investigation of Skiavounou et al. (13) on intra-osseous lesions at children and adolescence found ratio 1.25: 1 in

Table 1. Distribution of 152 cysts of the jaws in children and adolescents up to 18 years of age by age group, sex, location, histological type, reason for diagnostics, type of anesthesia and operative approach.

\begin{tabular}{|c|c|c|c|c|c|c|c|}
\hline \multicolumn{3}{|c|}{ Age groups } & $\begin{array}{c}\text { Up to } 4 \\
\text { years }\end{array}$ & $\begin{array}{c}5-9 \\
\text { years }\end{array}$ & $\begin{array}{c}10-14 \\
\text { years }\end{array}$ & $\begin{array}{c}15-18 \\
\text { years }\end{array}$ & Total \\
\hline \multirow{2}{*}{\multicolumn{2}{|c|}{ Patients }} & Number & 2 & 35 & 74 & 41 & 152 \\
\hline & & Per cent & $1.3 \%$ & $23.0 \%$ & $48.7 \%$ & $27.0 \%$ & $100 \%$ \\
\hline \multirow{4}{*}{ Sex } & \multirow{2}{*}{ male } & Number & 1 & 20 & 38 & 20 & 79 \\
\hline & & Per cent & $0.7 \%$ & $13.2 \%$ & $25 \%$ & $13.2 \%$ & $52 \%$ \\
\hline & \multirow{2}{*}{ female } & Number & 1 & 15 & 36 & 21 & 73 \\
\hline & & Per cent & $0.7 \%$ & $9.9 \%$ & $23.7 \%$ & $13.9 \%$ & $48 \%$ \\
\hline \multirow{4}{*}{ Location } & \multirow{2}{*}{ upper jaw } & Number & 1 & 5 & 20 & 20 & 46 \\
\hline & & Per cent & $0.7 \%$ & $3.3 \%$ & $13.2 \%$ & $13.2 \%$ & $30.3 \%$ \\
\hline & \multirow{2}{*}{ lower jaw } & Number & 1 & 30 & 54 & 21 & 106 \\
\hline & & Per cent & $0.7 \%$ & $19.7 \%$ & $35.5 \%$ & $13.9 \%$ & $69.7 \%$ \\
\hline \multirow{8}{*}{$\begin{array}{c}\text { Histological type } \\
\text { of cysts }\end{array}$} & \multirow{2}{*}{ radicular } & Number & - & 5 & 24 & 19 & 48 \\
\hline & & Per cent & - & $3.3 \%$ & $15.8 \%$ & $12.5 \%$ & $31.6 \%$ \\
\hline & \multirow{2}{*}{ dentigerous } & Number & 1 & 30 & 48 & 15 & 94 \\
\hline & & Per cent & $0.7 \%$ & $19.7 \%$ & $31.6 \%$ & $9.9 \%$ & $61.8 \%$ \\
\hline & \multirow{2}{*}{$\begin{array}{l}\text { odontogenic } \\
\text { keratocysts }\end{array}$} & Number & 1 & - & 2 & 1 & 4 \\
\hline & & Per cent & $0.7 \%$ & - & $1.3 \%$ & $0.7 \%$ & $2.6 \%$ \\
\hline & \multirow{2}{*}{ nonodontogenes } & Number & - & - & - & 6 & 6 \\
\hline & & Per cent & - & - & - & $3.9 \%$ & $3.9 \%$ \\
\hline \multirow{6}{*}{$\begin{array}{l}\text { Reason for } \\
\text { diagnostics }\end{array}$} & \multirow{2}{*}{ casual X-ray } & Number & - & 2 & 16 & 15 & 33 \\
\hline & & Per cent & - & $1.3 \%$ & $10.5 \%$ & $9.9 \%$ & $21.7 \%$ \\
\hline & \multirow{2}{*}{ painless mass } & Number & 2 & 30 & 43 & 16 & 91 \\
\hline & & Per cent & $1.3 \%$ & $19.7 \%$ & $28.3 \%$ & $10.5 \%$ & $59.9 \%$ \\
\hline & \multirow{2}{*}{ suppuration } & Number & - & 3 & 15 & 10 & 28 \\
\hline & & Per cent & - & $2.0 \%$ & $9.9 \%$ & $6.6 \%$ & $18.4 \%$ \\
\hline \multirow{4}{*}{$\begin{array}{c}\text { Type of } \\
\text { anesthesia }\end{array}$} & \multirow{2}{*}{ local } & Number & - & 1 & 14 & 13 & 28 \\
\hline & & Per cent & - & $0.7 \%$ & $9.2 \%$ & $8.6 \%$ & $18.4 \%$ \\
\hline & \multirow{2}{*}{ general } & Number & 2 & 34 & 60 & 28 & 124 \\
\hline & & Per cent & $1.3 \%$ & $22.4 \%$ & $39.5 \%$ & $18.4 \%$ & $81.6 \%$ \\
\hline \multirow{4}{*}{$\begin{array}{l}\text { Operative } \\
\text { approach }\end{array}$} & \multirow{2}{*}{ intraoral } & Number & 2 & 35 & 73 & 38 & 148 \\
\hline & & Per cent & $1.3 \%$ & $23.0 \%$ & $48.0 \%$ & $25.0 \%$ & $97.4 \%$ \\
\hline & \multirow{2}{*}{ extraoral } & Number & - & - & 1 & 3 & 4 \\
\hline & & Per cent & - & - & $0.7 \%$ & $2.0 \%$ & $2.6 \%$ \\
\hline
\end{tabular}


favour of male. The study of Lawoyin (14) comprising 2264 oral biopsies on patients from 1 to 16 years old found significant predomination of males while the study of Jones and Franklin (15) announced a sexual ratio of 1,01 . In the study of Lima et al. (16) made in 625 oral and maxillofacial biopsies in children younger than 14 females $(53 \%)$ were more than males $(47 \%)$.

In our study the most affected was the third age group i. e. between 10 and 14 years old. This is in accordance with the established by Bodner (10) average age of the patients with dentigerous cysts - 11.5 years old but differ from the information about average age of patients with radicular cysts -9.2 years old. Salako and Taiwo (11) report that the biggest number of cases with cysts was found in the ages between 11 and 16. The study of Gultelkin et al. (17) over 472 oral biopsies of children reported $60 \%$ of the cases in the age group from 6 to 12. Dhanuthai et al. (18) investigate 1251 oral lesions at children and reported for most frequent affection of the group with mixed dentition (49.24\%). In the study of Skiavounou et al. (13) dominate patients in the age group $13-18$ years old (58.7\%). Data given by Chen et al. (19), based on 534 oral biopsies at children younger than 15 shows that most affected patients were in the age group between 11 and 15. Sousa et al. (12) made investigation on 2356 oral biopsies reported that $70 \%$ of them were registered between the ages 9 and 14. Lima et al. (16) found the biggest part of patients with cysts $(89 \%)$ in the age group $7-14$.

Our study shows that jaw cysts in children and adolescence engage significantly the mandible with ratio mandible: maxilla as 2.3: 1. Information for predominant mandible localization is given by Lawoyin (14), Skiavounou et al. (13) and is in contrast with the data of Salako and Taiwo (11) and Lima et al. (16), that found more frequent affection of the maxilla.

Data received in our study show prevalence of dentigerous cysts $(61.8 \%)$, followed by radicular cysts (31.6\%). Dhanuthai et al. (18) confirm that dentigerous cysts were the most frequent oral pathology. Ochsenius et al. (20) found out that dentigerous cysts were the most frequent type of jaw cysts in patients between 0 and 15 years. In the study of Bodner (10) $45 \%$ from the cystic lesions at children were dentigerous cysts while the radicular cysts represented only $13.3 \%$. Lima et al. (16) presented dentigerous cysts as the most frequent type jaw cysts at children (8.64\%), followed by the radicular ones $(6.88 \%)$. Sousa et al. (12) determined that dentigerous cysts are secondly frequent $(6.5 \%)$ oral pathology but the most frequent type jaw cysts. These data oppose the determined by Skiavounou et al. (13) - in their study radicular cysts were the most frequent type (36.3\%), followed by the dentigerous cysts (18\%).

\section{Conclusions}

Jaw cysts at children and adolescence can be characterized with the following special features:

1. Affect constantly both sexes

2. There is a pick in development between the ages 10 and 14

3. More frequently affect the mandible

4. The predominant histological type is the dentigerous cyst

5. The most frequent clinical symptom painless swallow

6. Cystectomy is most frequently carried out by intraoral approach under general anesthesia

\section{References}

References with links to Crossref - DOI

1. Nair PN, Sjögren U, Sundqvist G. Cholesterol crystals as an etiological factor in non-resolving chronic inflammation: an experimental study in guinea pigs. Eur J Oral Sci. 1998;106:644-50.

2. Meghji S, Qureshi W, Henderson B, Harris M. The role of endotoxin and cytokines in the pathogenesis of odontogenic cysts. Arch Oral Biol. 1996;41:523-31.

3. Liapatas S, Nakou M, Rontogianni D. Inflammatory infiltrate of chronic periradicular lesions: an immunohistochemical study. Int Endod J. 2003;36:464-71.

4. Leonardi R, Caltabiano R, Loreto C. Collagenase-3 (MMP-13) is expressed in periapical lesions: an immunohistochemical study. Int Endod J. 2005;38:297-301.

5. Kubota Y, Yamashiro T, Oka S, Ninomiya T, Ogata S, Shirasuna $\mathrm{K}$. Relation between size of odontogenic jaw cysts and the pressure of fluid within. Br J Oral Maxillofac Surg. 2004;42:391-5.

6. Shibata Y, Asaumi J, Yanagi Y, Kawai N, Hisatomi M, Matsuzaki $\mathrm{H}$, et al. Radiographic examination of dentigerous cysts in the transitional dentition. Dentomaxillofac Radiol. 2004;33:17-20.

7. Reyes D, Villanueva J, Espinosa S, Cornejo M. Odontogenic calcificant cystic tumor: a report of two clinical cases. Med Oral Patol Oral Cir Bucal. 2007;12:E126-9.

8. Gallana-Alvarez S, Mayorga-Jimenez F, Torres-Gómez FJ, Avellá-Vecino FJ, Salazar-Fernandez C. Calcifying odontogenic cyst associated with complex odontoma: case report and review of the literature. Med Oral Patol Oral Cir Bucal. 2005;10:243-7.

9. Díaz-Fernández JM, Infante-Cossío P, Belmonte-Caro R, RuizLaza L, García-Perla-García A, Gutiérrez-Pérez JL. Basal cell nevus syndrome. Presentation of six cases and literature review. Med Oral Patol Oral Cir Bucal. 2005;10 Suppl 1:E57-66.

10. Bodner L. Cystic lesions of the jaws in children. Int J Pediatr Otorhinolaryngol. 2002;62:25-9.

11. Salako NO, Taiwo EO. A retrospective study of oral cysts in Nigerian children. West Afr J Med. 1995;14:246-8.

12. Sousa FB, Etges A, Corrêa L, Mesquita RA, de Araújo NS. Pediatric oral lesions: a 15-year review from São Paulo, Brazil. J Clin Pediatr Dent. 2002;26:413-8.

13. Skiavounou A, Iakovou M, Kontos-Toutouzas J, Kanellopoulou A, Papanikolaou S. Intra-osseous lesions in Greek children and adolescents. A study based on biopsy material over a 26-year period. J Clin Pediatr Dent. 2005;30:153-6.

14. Lawoyin JO. Paediatric oral surgical pathology service in an African population group: a 10 year review. Odontostomatol Trop. 2000;23:27-30

15. Jones AV, Franklin CD. An analysis of oral and maxillofacial pathology found in adults over a 30-year period. J Oral Pathol Med. 2006;35:392-401.

16. Lima Gda S, Fontes ST, de Araújo LM, Etges A, Tarquinio SB, Gomes AP. A survey of oral and maxillofacial biopsies in children: a single-center retrospective study of 20 years in Pelotas-Brazil. J Appl Oral Sci. 2008;16:397-402. 
17. Gültelkin SE, Tokman B, Türkseven MR. A review of paediatric oral biopsies in Turkey. Int Dent J. 2003;53:26-32.

18. Dhanuthai K, Banrai M, Limpanaputtajak S. A retrospective study of paediatric oral lesions from Thailand. Int J Paediatr Dent. 2007; 17:248-53.

19. Chen YK, Lin LM, Huang HC, Lin CC, Yan YH. A retrospective study of oral and maxillofacial biopsy lesions in a pediatric population from southern Taiwan. Pediatr Dent. 1998;20:404-10.

20. Ochsenius G, Escobar E, Godoy L, Peñafiel C. Odontogenic cysts: analysis of 2,944 cases in Chile. Med Oral Patol Oral Cir Bucal. 2007;12:E85-91. 